\title{
CORRECTION
}

View Article Online

View Journal I View Issue

\section{Correction: In situ crosslinking of electrospun gelatin for improved fiber morphology retention and tunable degradation}

Cite this: J. Mater. Chem. B, 2015,

3, 8212
A. P. Kishan, R. M. Nezarati, C. M. Radzicki, A. L. Renfro, J. L. Robinson, M. E. Whitely and E. M. Cosgriff-Hernandez*

DOI: $10.1039 / c 5 t b 90125 a$

Correction for 'In situ crosslinking of electrospun gelatin for improved fiber morphology retention and

www.rsc.org/MaterialsB tunable degradation' by A. P. Kishan et al., J. Mater. Chem. B, 2015, DOI: 10.1039/c5tb00937e.

Table 1 in the published article incorrectly indicates the statistical differences between percentage increases in fibre diameters for the $5 \times$ and $10 \times$ crosslinked meshes. A corrected version of Table 1 is shown below:

\begin{tabular}{lcc}
\hline Mesh & Degree of crosslinking (\%) & Increase in fiber diameter (\%) \\
\hline $1 \times$ & $32 \pm 6^{+, \times}$ & $170 \pm 13^{\mathrm{a}, \mathrm{b}}$ \\
$5 \times$ & $61 \pm 7^{+, *}$ & $9 \pm 5^{\mathrm{a}}$ \\
$10 \times$ & $91 \pm 1^{\times, *}$ & $10 \pm 4^{\mathrm{b}}$ \\
& $57 \pm 1$ & $24 \pm 9^{\mathrm{c}}$ \\
Glutaraldehyde & $61 \pm 7$ & $9 \pm 5^{\mathrm{c}}$ \\
$5 \times$ & Statistically significant differences between samples $(p<0.05)$ are indicated by pairs of matching superscript symbols $\left(+, \times,{ }^{*}, \mathrm{a}, \mathrm{b}, \mathrm{c}\right)$.
\end{tabular}

The Royal Society of Chemistry apologises for these errors and any consequent inconvenience to authors and readers. 